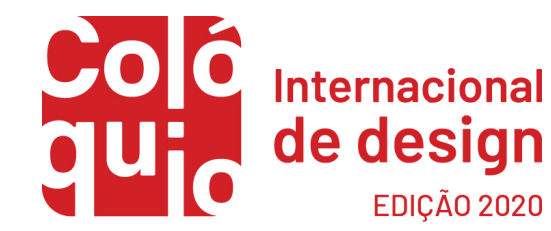

\title{
[Arte]fato para além do design
}

Marina Ciravegna da Rosa;

Debora Barauna;

Celso Carnos Scaletsky

\section{resumo:}

Arte e artefato são muitas vezes termos considerados distintos. Partindo da premissa de que artefatos são carregados de significado e que arte também expressa conceitos, o propósito é o de compreender a necessidade desta diferenciação. Este artigo buscou aprofundar, por meio de uma raiz comum, as relações entre as palavras arte e artefato. Foram consideradas suas distintas definições, de acordo com seus ambientes de origem, sendo esses, aqui, as artes plásticas e o design. Para tanto, foi construída uma narrativa, discutindo textos, principalmente, de Vilém Flusser e Herbert Simon. Foram perpassadas questões como: (1) O que é arte? (2) Natural ou artificial? (3) Qual a dialogia entre design e arte? (4) O contexto de consumo define o que é arte? Chegou-se a uma compreensão abrangente de que a classificação de um objeto como arte ou artefato pode ter pouca relevância, pois esta reside no expectador e não no criador.

\section{palavras-chave:}

arte; design; artefato 


\section{Introdução}

As palavras arte, artificial e artefato ficam em evidência nas diferenciações feitas por Simon (1981) a respeito da existência de duas dimensões: a natural e a artificial. A ciência do natural trata dos fenômenos do mundo, seus seres, suas características e propriedades (de como se comportam e atuam) e o artificial carrega consigo um corpo de conhecimento a respeito de objetos fabricados pelo ser humano (SIMON, 1981). As palavras 'artificial' e 'artefato' são etimologicamente derivadas do latim 'ars' (artes), sendo a primeira "ars+facere (fazer com arte)" (CUNHA, 2010, p.61) e a segunda "ars+factus (feito com arte)" (CUNHA, 2010, p.60), todas as duas com o sentido de "feito pelo homem' em oposição ao 'natural'. Levando em consideração que Cross (2001, p.54) sugere que "o que os designers sabem especialmente é o 'mundo artificial' - o mundo dos artefatos feitos pelo indivíduo" fica uma questão semântica e cultural para o designer: o que é arte? Ainda na linha da etimologia das palavras, ars (arte em latim) significa técnica ou habilidade. No entanto, como se verá no decorrer do artigo, existem autores que buscam diferenciar arte de artefato, incutindo no primeiro o sentimento e, no segundo a técnica. Neste ponto intervém Flusser (2007), lembrando que técnica e arte não são opostas e separá-las seria nefasto já que a técnica não pode ser oposta à arte, pois os artistas não são só inspiração. São também dotados de técnica e esmero na produção de seus objetos.

Muito da história da evolução humana pode ser contado, de acordo com Flusser (2007), pela ótica do Homo faber, que foi estabelecendo seu modus vivendi ao longo de sua evolução em relação à sua capacidade fabril. Passando de simples artesão, com pouco engenho e ferramentas à nossa atual organização social em torno de cidades e sistemas do homem-aparelho criando artificialidades tecnológicas. De acordo Bunge (2002, p.2561) "as coisas naturais, ao contrário das artificiais e feitas, vêm à existência e persistem independentemente dos humanos". Neste fazer, alguns designarão o resultado como artefato ou arte.

Este artigo busca aprofundar nas palavras arte e artefato através de sua raiz comum: arte e suas distintas definições de acordo com seu ambiente de origem, aplicabilidade e pontos de encontro com o design. O escopo será reduzido às artes plásticas relativas aos períodos ${ }^{1}$ Modernista (1850 a 1917) e Contemporâneo (1917 em diante) levando em consideração que o conceito de arte não é absoluto.

\section{0 propósito, o caráter e o ambiente}

Arte ou artefato nascem por um propósito e carregam consigo um caráter embutido pelo seu criador. Entretanto, propósito, o caráter e o ambiente em que esses são colocados e as interações que desses derivam, tendem a influenciar na criação do criador.

$\mathrm{Na}$ sequência deste tópico faremos uma discussão sobre a noção de artefato nas artes plásticas e no design.

\subsection{Artefato nas artes plásticas}

Uma pergunta de difícil resposta (tanto quanto 'o que é design?') é 'o que é arte?'. Um dos primeiros elementos que tornam esta resposta imprecisa é a alternância entre movimentos de arte ao longo da história. Tudo é relativo ao período histórico e à tendência dentro dele (os 'ismos' - expressionismo, cubismo, futurismo, abstracionismo, dadaísmo, surrealismo etc.). Outra questão é a atual discussão a respeito da necessidade de arte ser bela ou não (outra discussão sem um final previsto). De ser útil ou não. De ser capaz de comover ou incomodar. Estamos nos regendo por polaridades e, desta forma, começa a ficar mais compreensível definir 'o que não é arte' (outra forma de polaridade). De um modo en passant, a arte moderna (aqui definida como iniciada no período da revolução industrial) chega a ser considerada uma antiarte, mais preocupada com a mensagem a ser transmitida do que com a estética em si. Tem um caráter de manifesto para que o público reflita e não somente contemple as obras. A arte contemporânea (iniciada à época da I Guerra Mundial) é espontânea, pautada nas experimentações de técnicas e na exploração de mídias diferentes. Seu objetivo primário também é a reflexão, muitas vezes através do choque estético. Se faz necessário salientar que a apreciação da arte e o contexto da crítica estão relacionados ao período histórico, tanto do momento da criação da obra,

\footnotetext{
${ }^{1}$ Para ser fiel ao intervalo do percurso do desenvolvimento da disciplina do design, iniciado pelo design industrial
} 
quanto em relação à datação da análise e crítica realizada. Também relevante é 'fazer um esforço para ver como diferentes modelos de beleza coexistem em uma mesma época e como outros se remetem mutuamente através das diversas épocas (ECO, 2004). Efland (2005, p.179) afirma que "arte é uma forma de produção cultural que deve ser estudada dentro de seu contexto cultural". Quando Marcel Duchamp (artista francês) inscreve um mictório ${ }^{2}$ adquirido em uma loja de materiais de construção na Exposição dos Artistas Independentes de 1917 (Figura1), seu propósito é o de demonstrar que é "o artista quem decide o que é arte". Walton (2007), em seu livro 'Mimesis as Make Believe' (ainda sem tradução) reflete em relação à própria pergunta 'O que é arte?' e se os que a fazem expressam algo como uma única pergunta, ou se os que oferecem respostas estão, sequer, envolvidos no mesmo debate. Ele sugere que a própria profusão de respostas deveria nos oferecer uma pausa em relação ao assunto.

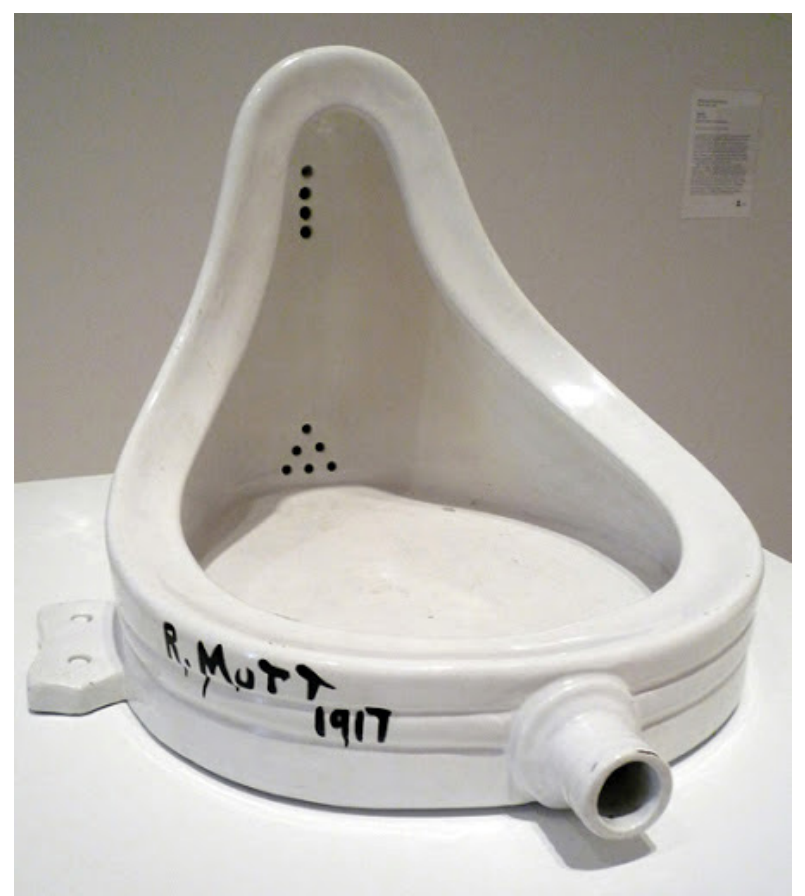

Figura 1 - Fonte, 1917/64 (réplica), porcelana, altura 33,5cm, Marcel Duchamp Fonte: Indiana Universiti Art Museum (Eskenazi Museum of Art)

\subsection{Artefato no design}

Assim como a discussão sobre arte ou artefato e seu modelo de 'consumo' nos museus e seu contexto, Gombrich (2013, p.28) afirma que "uma obra pode parecer muito distante quando pendurada na parede em sua moldura atrás de um vidro [...] as obras foram feitas para serem tocadas, como objetos de barganha, disputa e preocupação". O design não produz - pelo menos não declaradamente artefatos para fazerem parte de coleções de museus. Atualmente alguns destes objetos marcantes pela sua contribuição ao desenvolvimento das características de um período da sociedade estão em acervos de museus. Ao realizar a curadoria de uma exposição no MoMA (Talk to Me: Design and the Communication between People and Objects, 2011), a designer Paola Antonelli se viu na situação de precisar criar vários pontos de 'interatividade' virtual (Figura 2) para que os visitantes pudessem compreender o caráter, o propósito e o ambiente dos artefatos expostos.

\footnotetext{
${ }^{2}$ Marcell Duchamp vira o mictório ao contrário e assina como 'R. Mutt 1917' (seu pseudônimo, pois era um dos diretores da Sociedade dos Artistas Independentes, que organizaram a exposição, e não queria que seu nome estivesse na peça.
} 


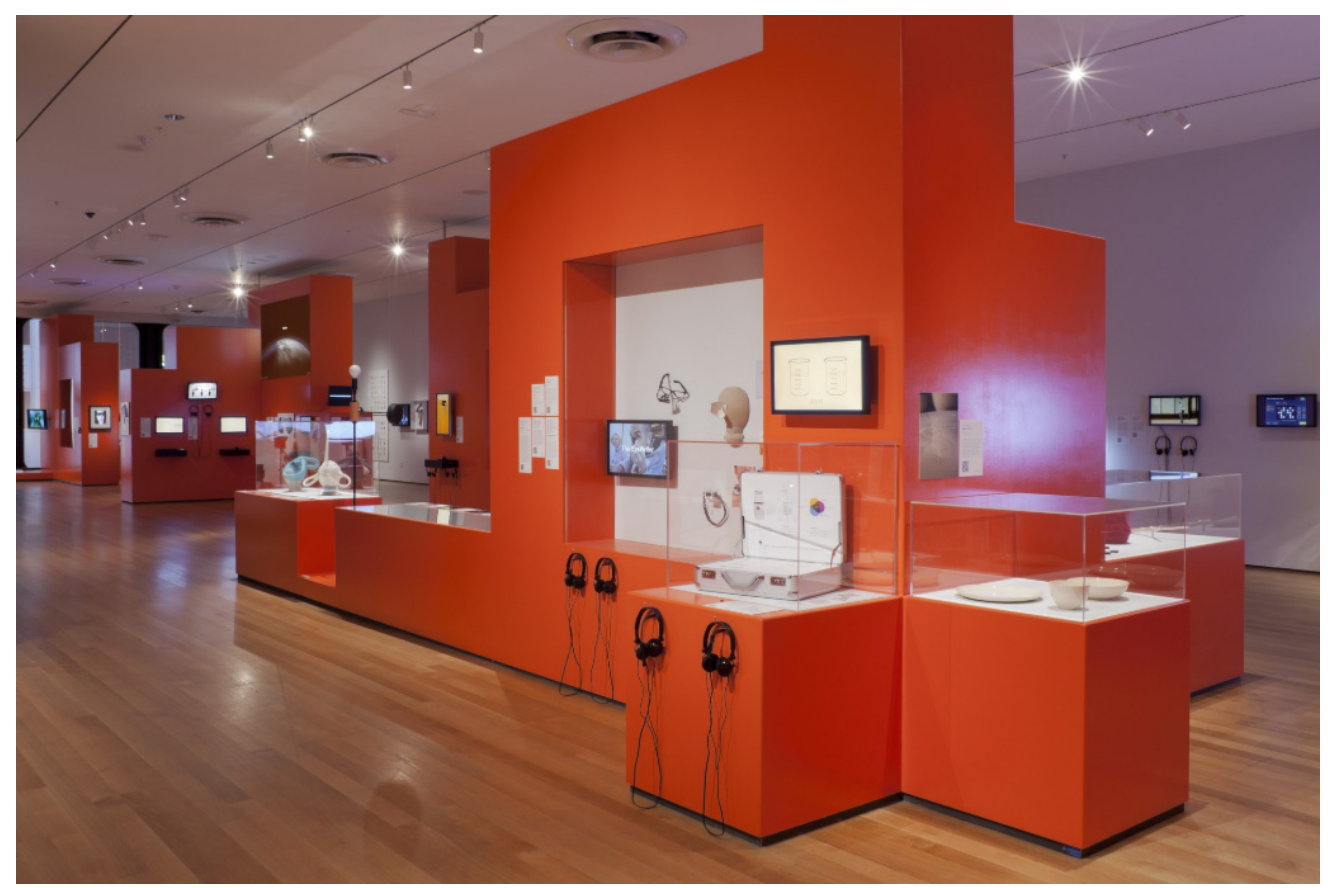

Figura 2 - Interatividade virtual no MoMA.

Fonte: MoMA (2011).

Como mostra a exposição, com todos os itens dentro de caixas acrílicas e protegidos do manuseio, muito da significação destes ficou à mercê do repertório individual dos visitantes. Mesmo considerando que em sua concepção original de contexto e uso os usuários ainda possam encontrar um significado distinto ao objeto do design no manuseio diário, em um museu, até esta possibilidade inexiste.

Em sua obra, Objetos do desejo, Forty (2013) faz um compilado da evolução do design iniciando em suas bases industriais até as identidades corporativas em que propõe uma análise sobre os objetos criados. Sob esta ótica, faz sentido a tentativa de distinção entre arte e artefato. A questão da 'boa forma' dos objetos entremeia a própria discussão em relação ao design e o estudo das artes como base da formação do designer. A Tabela 1 busca evidenciar a dicotomia proposta no texto de Forty (importante salientar que os autores não corroboram todos os itens propostos na tabela, mas que esta foi trazida para ilustrar o caráter utilitário da dicotomia).

\begin{tabular}{l|l|l} 
& \multicolumn{2}{|c}{ Tabela 1 - Forty e a diferenciação entre arte e artefato } \\
\hline Quanto à concepção & $\begin{array}{l}\text { os objetos de arte são em geral concebidos e } \\
\text { feitos por (ou sob a direção de) uma pessoa, o } \\
\text { artista }\end{array}$ & $\begin{array}{l}\text { enquanto isso não é verdade para os } \\
\text { bens manufaturados }\end{array}$ \\
\hline Quanto à autonomia & $\begin{array}{l}\text { A concepção e a fabricação de sua obra } \\
\text { permitem aos artistas considerável autonomia }\end{array}$ & $\begin{array}{l}\text { produção de artefatos, um processo } \\
\text { no qual o design faz parte sendo } \\
\text { inserido em um processo maior }\end{array}$ \\
\hline Quanto à função & $\begin{array}{l}\text { principais funções da arte é dar livre expressão à } \\
\text { criatividade e à imaginação }\end{array}$ & é dar lucro para o fabricante
\end{tabular}

Fonte: Autores (2020) baseado em Forty (2013, p.13).

Diversos aspectos propostos pelo autor poderiam ser questionados. Por exemplo, se a função primordial do design seria "dar lucro ao fabricante". Na verdade, existem variadas dimensões dos produtos do design, sendo o "dar lucro" uma delas. Igualmente, a criatividade e a livre expressão são componentes importantes do fazer design. Fica evidente que toda arte é artificial. De acordo com Flusser (2007) o homem pré-moderno tentava interpretar o mundo enquanto nós, pessoas pósmodernas criamos artes que são produtos da tecnologia, pois buscamos interpretar as teorias referentes ao mundo. Ainda mais, ele chama a atenção ao fato de que há, cada vez mais, a distinção de "conceito objeto, do conceito matéria, e a projetar objetos de uso imateriais" (FLUSSER, 2007, p.197). 
No fazer artístico reside tanta engenhosidade, tanto sentir e expressar que esta afirmação (de que 'toda arte é artificial') soa taxativa, embora seja acurada. Na introdução (escrita por Rafael Cardozo) à edição brasileira do livro de Flusser (2007), há uma contextualização significativa deste entendimento: "a base de toda a cultura é a tentativa de enganar a natureza por meio da tecnologia, isto é, da maquinação. Fazemos isso com tamanha engenhosidade que o mundo parece corresponder ao sistema conceitual que impingimos a ele" (FLUSSER, 2007, p.14).

\subsection{Arte e design}

Muito embora seja comum encontrar um designer que se intitule artista, será bem mais difícil localizar um artista que receba, também, a alcunha de designer. $O$ design não esteve inerte aos períodos artísticos mencionados para este artigo (Modernista e Contemporâneo), muito pelo contrário, há uma profusão de precursores do design que foram, também, arquitetos ${ }^{3}$ e artistas, como o caso de Peter Behrens (arquiteto e designer alemão), Walter Gropius (arquiteto alemão), e das escolas Bauhaus e de Arte de Chicago e tantos outros nomes que demonstraram, através de seus projetos, esta relação intrínseca entre as duas áreas de conhecimento. Para além da argumentação de Flusser (2007) de que o design é um lugar em que arte e técnica se encontram, há um grande ponto de contato entre arte e design - que já foi amplamente estudado - que é a estética. Neste artigo, não entraremos neste detalhamento (por limitações do formato), mas vale à pena citar três aspectos da convergência elaborados por Lupo (2011): (1) função estética dos objetos como um dos primeiros pontos de interseção entre arte e design, (2) arte/estética como um lugar para experimentação do design e (3) similaridades entre arte e design dizem respeito a ambos: formas e processos. Na Figura 3 vemos uma colagem de imagens de artefatos criados por Peter Behrens não só de forma a atender a utilidade proposta, mas com uma clara preocupação estética ${ }^{4}$.

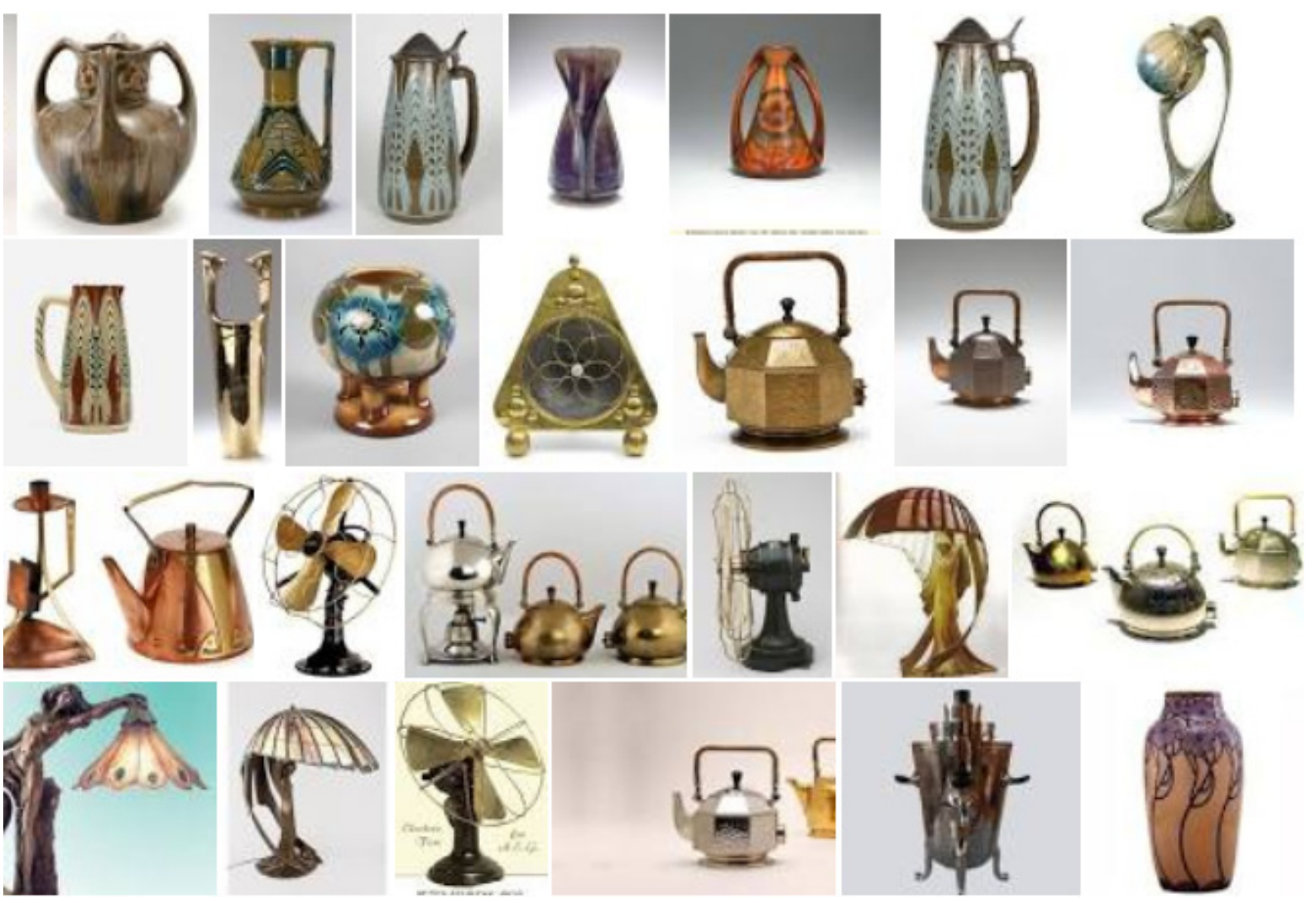

Figura 3 - Compilação de artefatos criados por Peter Behrens

Fonte: sites diversos com obras do designer e arquiteto Peter Behrens (fotos disponiveis para reprodução)

\footnotetext{
${ }^{3} \mathrm{Na}$ relação design e arquitetura sempre houve uma sobreposição de profissões, sendo mesmo considerado no passado uma só profissão. Isto deriva, em parte, da palavra design, frequentemente e intensamente utilizado na língua inglesa como "projeto".

${ }^{4}$ Fica a provocação: objetos de uso ou de arte?
} 
Aforismos, assim como dualismos, não comportam as dimensões humanas. São modelos reducionistas, úteis, sem dúvida, em um momento de compreensão, mas rasos no sentido de elucidar as capacidades humanas e suas complexidades. Dijon de Moraes (2008) elaborou um elenco (Quadro 1) no seu livro 'Limites do Design' e mostra em parte, esse esforço de distinção de contextos, mundos, linguagens, histórias, culturas e homens com os quais o design convive.

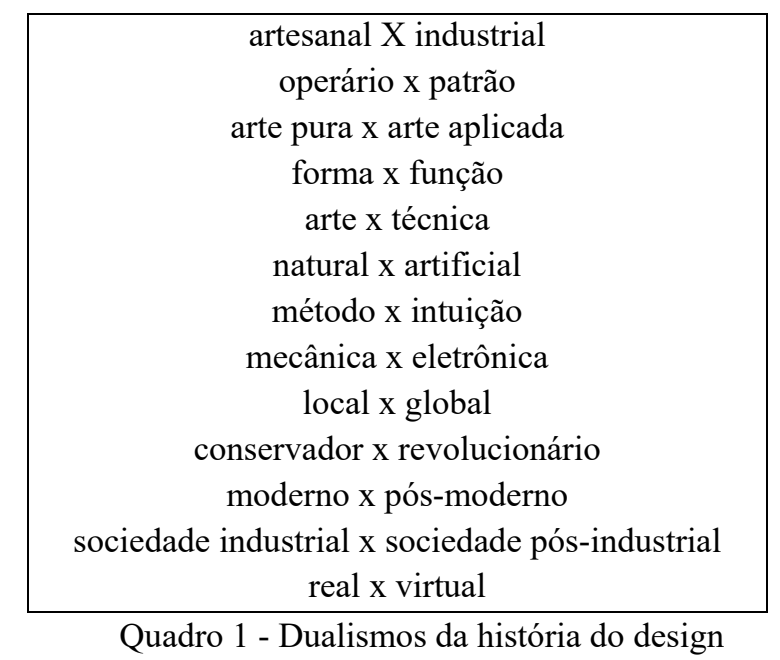

Se faz relevante mencionar o caráter polissêmico dos objetos individuais, comportando seus múltiplos significados e capazes de serem colocados em muitas formas diferentes de categorização. Estes objetos individuais, ou 'objetos de uso', testemunham um mundo de emoções, pensamentos e evocam conhecimentos somente significativos em seu contexto, além de serem uma "mediação entre mim e outros homens, e não meros objetos" (FLUSSER, 2007, p195). Essa mediação proposta por Flusser (2007) para o 'objeto de uso' pode ser elevada a uma linguagem da arte, do artefato, do artificial.

A arte é a linguagem das sensações, que faz entrar nas palavras, nas cores, nos sons ou nas pedras. A arte não tem opinião. A arte desfaz a tríplice organização das percepções, afecções e opiniões, que substitui por um monumento composto de perceptos, de afectos e de blocos de sensações que fazem as vezes de linguagem (DELEUZE \& GUATTARI, 1992, p. 232).

Frayling (1993), embora anterior, é consoante a Flusser (2007) e afirma que a pesquisa em arte e design é espinhosa e está dentro e fora do objeto:

Pesquisa onde o produto final é um artefato - onde o pensamento é, por assim dizer, incorporado no artefato, onde o objetivo não é principalmente o conhecimento comunicável no sentido da comunicação verbal, mas no sentido da comunicação visual, icônica ou imaginária. Eu mencionei a tradição cognitiva na arte, e isso me parece ser uma tradição da qual muitas pesquisas futuras poderiam crescer: uma tradição que fica do lado de fora do artefato ao mesmo tempo em que fica dentro dele (FRAYLING, 1993, p.5)

As duas citações acima exemplificam o caráter de comunicação, de linguagem, presentes no mundo artificial da arte e do artefato em seu contexto. A escolha do título desta seção 'O propósito, o caráter e o ambiente' faz referência a três termos apresentados por Simon (1981) que levam em consideração o ambiente como matriz. Seu objetivo é o de apresentar como o propósito e o caráter do artefato podem ser interpretados ou alterados de acordo com o ambiente e suas variáveis.

Neste artigo, os termos acima citados de Simon (1981) (o caráter, o propósito e o ambiente) foram tomados de empréstimo para afirmar o potencial de linguagem, de significação, nas diversas 
interpretações da palavra artefato de acordo com o momento histórico, interlocutores e objetivos de uso ou apreciação.

Flusser (2007) sustenta que os artefatos são suportes de informação bem como que a arte oferece a capacidade de gerar modelos (2007). Deleuze e Guattari (1992) sustentam que a arte é a linguagem das sensações. Arte e Design possuem, ambas, doses de objetividade e subjetividade e se ocupam (e não somente estas áreas de saber) de formas de linguagem, da comunicação de ideias, de conceitos, modelos, de sentidos e sentimentos. O design e seus artefatos são carregados de significado, estética e informação. Estes elementos nos remetem à capacidade e necessidade de comunicação, de compreensão de linguagens e o que estas transmitem ou intentam transmitir.

\subsection{Artefato para além da dimensão material}

Retomemos a etimologia das palavras artificial e artefato, que são derivadas do latim 'ars' e sua relação com o fazer, o laborar, o artificiar a arte

Arte no Artefato - "feito com arte" - resultado do que é feito com arte - leva ao entendimento que arte é um processo, uma técnica e/ou que está imbricado no ato de fazer com

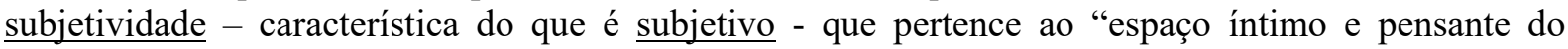
sujeito, do indivíduo (seu mundo interno), a partir do qual ele se relaciona com (se lança sobre) o mundo objetivo (mundo externo, social e natural), dando-lhe sentido, ou seja, produzindo, fundando, colocando, instaurando o real, o mundo, as coisas" (PAN et al., 2011, p.3). Na perspectiva de artefato como algo físico feito com arte, poderia se dizer que a arte está no artefato pela dimensão material processo, técnica, de manipular materiais; pela dimensão imaterial (subjetividade - cultura humana) e que essas dimensões assumem sentidos diferentes a partir de pontos de vistas de distintos sujeitos que interagem com o objeto, como o(s) designer(s) ${ }^{5}$ e os usuários ${ }^{6}$.

Já Arte no artificial - "fazer com arte" - refere-se ao processo ou à técnica, pelo qual é feito, que, no caso, não é natural, mas sim construído pelo ser humano. No entanto, se considerarmos arte como a subjetividade imbricada ao processo levanta-se a questão: se "fazer com arte" é natural ou artificial ou uma mistura dos dois? O ser humano e o pensamento são naturais pela perspectiva da biologia, um ser e sistema orgânico. Pela perspectiva da filosofia os seres humanos são artificiais pois são feitos por si e para si (CUNHA, 2010). Porém, ao mesmo tempo, o desenvolvimento humano é algo construído através das múltiplas relações/interações dele com o mundo - esta é uma perspectiva vygotskyana da aprendizagem (socioconstrutivismo). Na neurociência o pensamento vem de redes neurais plásticas, processos mentais e cognitivos que se modificam, física e quimicamente, com a aprendizagem. Não que essas duas últimas áreas digam que isto seja artificial, mas sim que é construído e (re)programado/manipulado respectivamente. Por exemplo, no design tenta-se entender o indivíduo para manipular artefatos para eles: Design emocional e Neurodesign são tipos de abordagens que estudam sentimentos e mentes para produzir respostas (em artefatos) mais positivas às formas humanas de sentir e pensar. Enfim, na própria perspectiva do design, há pontos de vistas distintos sobre o pensamento do designer. Dorst (2004) compreende este como algo natural, nato, nativo do designer. Já Manzini (2006) entende o design como um processo de aprendizagem social. Todavia, o autor reconhece também que os indivíduos, como designers difusos, são dotados de capacidades humanas naturais de senso crítico, criatividade e senso prático (MANZINI, 2017). Schön (2003, p. 38) fala da nossa capacidade artística. Nossa capacidade de lidar com problemas mal estruturados seria possível em parte por nosso talento artístico. Gombrich (2013, p. 27) também afirma que todos temos o dom artístico, desde que desenvolvidas estas capacidades. Assim, não há respostas exatas na relação entre 'fazer com arte' como técnica ou subjetividade, apenas interpretações.

\footnotetext{
${ }^{5}$ Designers - os sentidos são embutidos no ato de criar-interpretação do designer ou intérpretes do processo de design, sendo esses: designers especialistas e não designers difusos (definições de MANZINI, 2016; 2017).

${ }^{6}$ Usuários - os sentidos são adquiridos pela relação desses sujeitos com os artefatos, diante de seus repertórios individuais de vida (interpretações próprias dos usuários). Porém, por outra ótica, os usuários também podem se cocriadores, quando inseridos no processo de criação, configurando-se como um designer difuso). Por isto se justifica os processos de cocriação e prototipagem rápida - o objetivo é aprender com os usuários, antecipando a criação de sentidos por esses.
} 
Criar e conceber tem a ver com processos de subjetividade e pensamento. Construir tem relação com processos de desenvolvimento do que já foi criado pela subjetividade e pensamento (usase da cultura imaterial). Aqui também se insere o pensamento, mas como pensamento para a prática, técnica de construção por ferramentas, instrumentos para a manipulação de materiais.

\section{Conclusão}

Este artigo buscou compreender ${ }^{7}$ a imposição de separação entre arte e artefato. Um artefato é todo objeto feito pelo homem com uma intensão (para o design, nem todo artefato é físico). Sendo assim, não existe distensão entre arte e artefato. Fica clara a necessidade, em primeira instância, da observância do propósito, do caráter e do ambiente que um objeto assume, seja ele classificado (pelo interpretador) como arte ou artefato. Desconhecer estas três dimensões tornam menores as possibilidades de fruição desta forma artificial de contato com uma cultura, seu tempo e suas representações simbólicas, bem como uma linguagem estética.

\footnotetext{
${ }^{7}$ Muito embora careça de mais aprofundamento e pesquisas (como as dimensões da semiótica, da estética e da beleza). Uma outra linha de estudo futura seria a relação de artefatos de design e museus.
} 


\section{[Art]ifact beyond design}

Abstract: Art and artifact are often terms that are considered distinct. Starting from the premise that artifacts are loaded with meaning and that art also expresses concepts, the purpose is to understand the need for this differentiation. This article sought to deepen, through a common root, the relationships between the words art and artifact. Their different definitions were considered, according to their original environments, which are, here, the plastic arts and design. For this, a narrative was built, discussing texts, mainly, by Vilém Flusser and Herbert Simon. Questions such as: (1) What is art? (2) Natural or artificial? (3) What is the dialog between design and art? (4) Does the context of consumption define what art is? A comprehensive understanding was reached that the classification of an object as art or artefact may have little relevance, as it resides in the viewer and not in the creator.

Keywords: art; design; artifact

\section{Referências}

BUNGE, M. Dicionário de Filosofia. Tradução de Gita K. Guinsburg. São Paulo: Perspectivas, 2002.

CROSS, N. Designerly Ways of Knowing: Design Discipline Versus Design Science. Cambridge: MIT Press. 2001.

CUNHA, Antonio Geraldo da. Dicionário Etimológico da Língua Portuguesa. 4 ed.Brasil:Lexikon Editorial, 2010, 101p.

DELEUZE, G.; GUATTARI, F. O que é a filosofia? São Paulo: Editora 34, 1992

ECO, U. História da beleza. Rio de Janeiro: Record, 2004.

EFLAND, A. Cultura, sociedade, arte e educação num mundo pós-moderno. São Paulo: Perspectiva, 2005.

FLUSSER, V. O mundo codificado: por uma filosofia do design e da comunicação. $1^{a}$ ed. São Paulo: Cosacnaify, 2007.

FORTY, A. Objeto de desejo: design e sociedade desde 1750. São Paulo: Cosac Naify, 2013.

FRAYLING, C. Research in Art and Design. Royal College of Art Research Papers, v. 1, n. 1, p.115, 1993.

GOMBRICH, E. H. A história da arte. Rio de Janeiro: LTC, 2013.

GOMPERTZ, W. Isso é arte? Rio de Janeiro: Zahar, 2013.

LUPO, E. Design, arts and "aesthetics of innovation. Strategic Design Research Journal, v.4, n.2, p.40-53, 2011.

MANZINI, E. Design; quando todos fazem design: uma introdução ao design para a inovação social. São Leopoldo: UNISINOS, 2017.

MoMA. Talk to Me: Design and the Communication between People and Objects. Disponível em: <https://www.moma.org/calendar/exhibitions/1071>. Acesso em: 15 de junho de 2020.

MORAES, D. Limites do design. São Paulo: Studio Nobel, 2008.

PAN, M. A. G. S.; ROSSLER, J. H., FERRARINI, N. L.; VALORE, L. A.; OLIVEIRA, S. N. Subjetividade: um diálogo interdisciplinar. Interação em psicologia, v.15, p.1-13, 2011. 
SCHÖN, D. Educando o profissional reflexivo. Porto Alegre: ARTMED, 2003.

SIMON, H. As ciências do artificial. $1^{a}$ ed. São Paulo: Almedina, 1981

WALTON, K. Aesthetics-What? Why? and Wherefore? The Journal of Aesthetics and Art Criticism, v. 65, n.2, 147-161, 2007. 